\title{
Comparison of the lipid compositions of the aortic lesions in rabbits given different atherogenic diets
}

\author{
By J. H. MOORE* \\ National Institute for Research in Dairying, Shinfield, Reading \\ (Received iा Fanuary 1967-Accepted 21 April 1967)
}

\begin{abstract}
I. The compositions of the lipids in the atheromatous lesions of rabbits have been studied in an experiment in which two groups of rabbits (twelve/group) were given different atherogenic diets for a period of 38 weeks. One group of rabbits was given a diet in which $35 \%$ of the total calories was derived from butterfat and the other group was given a diet in which $48 \%$ of the total calories was derived from starch.

2. At the end of the feeding period the rabbits were killed and the atheromatous plaques were dissected out from the aortic intima of each rabbit. The lipid compositions of the aortic lesions were determined and the results compared with the compositions of the plasma lipids.

3. In the lipids of the aortic lesions in the rabbits given the high-butterfat diet, the proportions of cholesterol and cholesterol esters were higher and the proportion of triglycerides was lower than in the lipids of the aortic lesions in the rabbits given the high-starch diet. Irrespective of dietary treatment, free cholesterol constituted a higher proportion of the lesion lipids than it did of the plasma lipids.

4. In the rabbits on either dietary treatment, the lesion cholesterol esters contained higher concentrations of oleic acid and lower concentrations of linoleic acid than did the plasma cholesterol esters. In the lesion phospholipids there were higher concentrations of palmitic, palmitoleic, stearic and oleic acids and lower concentrations of linoleic and arachidonic acids than in the plasma phospholipids.

5. In both groups of rabbits the phospholipids of the aortic lesions contained higher proportions of cephalin and sphingomyelin and lower proportions of lecithin than did the plasma phospholipids.

6. The results of this investigation are discussed in relation to the possible origins of the lipids in the aortic lesions of the experimental rabbits.
\end{abstract}

The work of Moore \& Kon (1963) and Moore \& Williams (1964b) has shown that rabbits develop aortic atherosis when given semi-purified diets containing no added cholesterol but in which the major proportion of the total calories is supplied either as butterfat or starch. The histological appearances of the atheromatous lesions in the aortas of the rabbits given the high-butterfat diet or the high-starch diet have been described by Moore \& Williams (1964b). These atheromatous lesions resemble the early aortic lesions observed in man (Constantinides, Booth \& Carlson, 1960). When examined by ordinary light, histological sections of the aortic lesions obtained from the rabbits on either dietary treatment appeared similar with respect to the intensity of the Sudan IV stain that had been taken up by the lipid deposits. This indicated that similar amounts of total lipid had been deposited in the aortic lesions of the rabbits given either of the two atherogenic diets. However, when the sections were examined by polarized light, the concentration of birefringent material in the aortic lesions of the rabbits given the high-butterfat diet appeared considerably greater than that in the aortic lesions of the rabbits given the high-starch diet (Moore, unpublished observations). Although such observations must be interpreted with extreme caution, it

* Present address: The Hannah Dairy Research Institute, Ayr, Scotland. 
seemed possible that in the aortic lesions of the rabbits given the high-butterfat diet, cholesterol constituted a higher proportion of the total lipid than it did in the aortic lesions of the rabbits given the high-starch diet. To investigate this possibility the compositions of the lipids extracted from the aortic lesions of rabbits given the highbutterfat diet or high-starch diet have been determined. The results of this study are now reported together with a comparison of the compositions of the lesion and plasma lipids obtained from rabbits on either of the two dietary treatments.

\section{EXPERIMENTAL}

\section{Rabbits, diets and experimental procedure}

Twenty-four male New Zealand White rabbits of one strain were obtained at the age of 6 months from a local breeder. On arrival at the laboratory, the animals were housed in individual metal metabolism cages and were given a commercial rabbit diet for a short period until they became accustomed to their surroundings. The rabbits were then randomly divided into two groups of twelve each and the commercial diet was gradually replaced by the two experimental diets during a 4 -week period, by which time all the animals were readily consuming the experimental diets. The experimental diets were given to the animals for a period of $3^{8}$ weeks. Throughout the whole experiment, the rabbits were given food and water ad lib.

The percentage composition of the high-butterfat diet was: butterfat 20 , wheat starch (Starch Products Ltd, Slough, Bucks.) 16.3, sucrose Io, casein (lactic acid casein; Glaxo Research Ltd, Greenford, Middx.) 25.0, Solkafloc (grade BW 40; Johnsen, Jorgensen and Wettre Ltd, London, EC 4 ) I9.0, methyl cellulose (Celacol M.450; J. M. Steel and Co. Ltd, London, WC 2) I.0, potassium acetate $2 \cdot 5$, magnesium oxide 0.5 , sodium chloride 0.7 , choline chloride 0.5 , salt mixture 4.0 and vitamin mixture 0.5 . The percentage composition of the high-starch diet was: maize oil 0.4 , wheat starch $48 \cdot 1$, sucrose $8 . \mathrm{I}$, casein 20.2 , Solkafloc ${ }_{15} .4$, methyl cellulose 0.8 , potassium acetate $2 \cdot 0$, magnesium oxide 0.4 , sodium chloride $0 \cdot 6$, choline chloride 0.4 , salt mixture 3.2 and vitamin mixture 0.4 . No cholesterol was added to either of the two experimental diets. The methods of preparing the butterfat and pelleting the diets have been given by Moore \& Williams $(1964 b)$, as have the compositions of the salt and vitamin mixtures. As explained by Moore \& Williams $(1964 b)$, these two experimental diets were designed so that the ratio of linoleic acid to gross energy was the same for each diet.

At the end of the feeding period the animals were killed by a blow on the head and, as rapidly as possible thereafter, the aorta, extending to the point of division into the two common iliac arteries, was removed from each rabbit.

\section{Treatment of tissues and methods of analysis}

The aortas were cut open longitudinally and the intimal surfaces were washed briefly with $0.9 \%(\mathrm{w} / \mathrm{v})$ sodium chloride solution. The intimal layer, including the internal elastic membrane, was removed from each aorta and the atheromatous plaques were dissected out from the normal intimal tissues. To obtain sufficient lipid 
for analysis, the atheromatous plaques obtained from the aortas of the rabbits on each dietary treatment were pooled into four samples so that each pooled sample contained the atheromatous plaques obtained from three rabbits.

The lipids were extracted from the pooled samples of atheromatous lesions by the method of Folch, Lees \& Stanley (1957). The methods used for the fractionation and analysis of cholesterol, cholesterol esters, triglycerides, unesterified fatty acids and total phospholipids in the eight samples of lesion lipids have been given in detail by Moore (I962), Moore \& Doran (1962) and Moore \& Williams (I966a). When these analyses were complete, the remainder of the four lipid extracts obtained from the aortic lesions of the rabbits on each dietary treatment were combined so that the lesion phospholipids could be examined in greater detail. The phospholipids in the two combined extracts were fractionated and analysed by the methods described by Noble \& Moore (1965). The fatty-acid compositions of the various lipid fractions were determined as described by Moore \& Williams (1963, I964a).

\section{RESULTS}

As observed in previous experiments (Moore \& Kon, I963; Moore \& Williams, $1964 b$ ), the degree of aortic atherosis in the rabbits given the high-butterfat diet was the same as that in the rabbits given the high-starch diet. In each group of rabbits the aortic lesions were confined to the intima, and histological examination revealed the presence of extensive amounts of lipid deposited between the internal elastic membrane and the endothelial surface. This lipid material appeared to be present either extracellularly as fine droplets scattered throughout the ground substance or intracellularly as accumulations in lipid-laden phagocytes. The atheromatous lesions in both groups of rabbits appeared identical when sections were examined under ordinary light, but when sections were examined under polarized light the lesions in the aortas of the rabbits given the high-butterfat diet appeared to contain higher concentrations of birefringent material.

In Tables $1-5$ the results for the various lipid components of the aortic lesions obtained from the rabbits on each dietary treatment are given as the means and standard errors of the means of four pooled samples of lesion lipids. For com parison, $m$ ean values for the corresponding lipid components of the plasma of rabbits given eit her the high-butterfat diet or the high-starch diet are also presented in Tables $\mathrm{I}-5$. It must be emphasized, however, that these mean values for the plasma lipids were obtained from previous experiments, the detailed results of which have appeared in e arlier publications (Moore \& Williams, I964c, $d, 1965,1966 a, b$ ). Nevertheless, comparison of the compositions of the plasma and lesion lipids seemed justified since, in the previous experiments and in the one now reported, the compositions of the corresponding experimental diets were identical, as were the breed and strain of experimental rabbits, the age of the animals at the beginning of the experiment and the duration of the feeding period. Moreover, it has been observed in the author's laboratory that the composition of the plasma lipids of rabbits given a particular diet does not differ appreciably from experiment to experiment. The mean concentrations 
of total lipid and total cholesterol in the plasma of the rabbits given the high-butterfat diet were $45 \mathrm{I}$ and $\mathrm{I}_{5} \mathrm{I} \mathrm{mg} / \mathrm{I} / 00 \mathrm{ml}$ respectively. The mean concentrations of total lipid and total cholesterol in the plasma of the rabbits given the high-starch diet were 262 and $85.4 \mathrm{mg} / 100 \mathrm{ml}$ respectively. The values for the plasma lipids of the rabbits given the high-butterfat diet are means derived from a group of thirteen animals, whereas the corresponding values for the rabbits given the high-starch diet are means derived from a group of twelve animals.

Table I. Compositions* of the lipids present in the aortic lesions $\uparrow$ and plasma given different atherogenic diets

\begin{tabular}{|c|c|c|c|c|}
\hline \multirow[b]{2}{*}{ Constituent } & \multicolumn{2}{|c|}{ Butterfat diet } & \multicolumn{2}{|c|}{ Starch diet } \\
\hline & $\begin{array}{l}\text { Aortic } \\
\text { lesions }\end{array}$ & Plasma & $\begin{array}{l}\text { Aortic } \\
\text { lesions }\end{array}$ & Plasma \\
\hline Free cholesterol & $19 \cdot 0 \pm 0.89$ & $8 \cdot 6$ & $12 \cdot 5 \pm I \cdot 14$ & $9 \cdot 6$ \\
\hline Cholesterol esters & $34 \cdot 0 \pm I \cdot 45$ & $3^{8 \cdot 9}$ & $24 \cdot 5 \pm 1 \cdot 10$ & $37 \cdot 4$ \\
\hline Triglycerides & $I I \cdot 8 \pm I \cdot 46$ & $14 \cdot 6$ & $28 \cdot 3 \pm 0.97$ & $22 \cdot 6$ \\
\hline Unesterified fatty acids & $4.8 \pm 0.52$ & 3.6 & $3 \cdot 9 \pm 0.73$ & $3 \cdot 8$ \\
\hline Phospholipids & $30 \cdot 6 \pm 2 \cdot 73$ & $34 \cdot 3$ & $30.9 \pm 0.76$ & $26 \cdot 7$ \\
\hline
\end{tabular}

The compositions of the lipids isolated from the aortic lesions and the plasma of rabbits given the high-butterfat diet or the high-starch diet are presented in Table I. Cholesterol and cholesterol esters together accounted for over $50 \%$ of the lesion lipids obtained from the aortas of the rabbits given the high-butterfat diet but for only $37 \%$ of the lesion lipids obtained from the aortas of the rabbits given the high-starch diet. The proportion of triglycerides in the lipids of the aortic lesions of the rabbits given the high-starch diet was considerably greater than that in the lipids of the aortic lesions of the rabbits given the high-butterfat diet. It should be noted that the proportion of triglycerides in the total plasma lipids of the rabbits given the high-starch diet was also higher than that in the plasma lipids of the rabbits given the high-butterfat diet. The lipids extracted from the aortic lesions in both groups of rabbits contained the same proportion of total phospholipids and similar proportions of unesterified fatty acids. In the rabbits on both dietary treatments about $70 \%$ of the plasma cholesterol occurred as cholesterol esters, whereas only about $50 \%$ of the lesion cholesterol was present in the esterified form. Irrespective of dietary treatment, free cholesterol constituted a higher proportion of the lesion lipids than it did of the plasma lipids.

The fatty-acid compositions of the cholesterol ester fractions present in the aortic lesions and in the plasma of rabbits given either of the two atherogenic diets are presented in Table 2 in which, and elsewhere in this paper, the shorthand designation suggested by Farquhar, Insull, Rosen, Stoffel \& Ahrens (1959) is used to denote individual fatty acids. The fatty acids listed in Table 2 (and in Tables 3,4 and 5) accounted for about $95 \%$ of the total fatty acids present. The remaining $5 \%$ consisted of trace concentrations of fatty acids that were tentatively identified as $15: 0,17: 0$, 
$17: 0 \mathrm{br}, 18: 3,20: 1,20: 2$ and $20: 3$. There was a broad similarity in the fatty-acid compositions of the cholesterol esters in the aortic lesions of the two groups of rabbits and, as in the plasma cholesterol esters, oleic acid was the major constituent fatty acid. However, in the rabbits on each dietary treatment, the concentrations of oleic acid in the lesion cholesterol esters were greater than the concentrations of this fatty acid in the plasma cholesterol esters. On the other hand, the concentrations of linoleic acid in the lesion cholesterol esters were less than the concentrations of this dienoic acid in the plasma cholesterol esters.

Table 2. Fatty-acid compositions * of the cholesterol esters isolated from the aortic lesions $\uparrow$ and plasma of rabbits given different atherogenic diets

\begin{tabular}{|c|c|c|c|c|}
\hline \multirow[b]{2}{*}{$\begin{array}{l}\text { Fatty } \\
\text { acid }\end{array}$} & \multicolumn{2}{|c|}{ Butterfat diet } & \multicolumn{2}{|c|}{ Starch diet } \\
\hline & $\begin{array}{l}\text { Aortic } \\
\text { lesions }\end{array}$ & Plasma & $\begin{array}{l}\text { Aortic } \\
\text { lesions }\end{array}$ & Plasma \\
\hline $16: 0$ & $16 \cdot 9 \pm I .40$ & $18 \cdot 1$ & $16.9 \pm 0.62$ & 17.9 \\
\hline I6: I & $3.2 \pm 0.32$ & $3 \cdot 5$ & $5 \cdot 1 \pm 0.32$ & $6 \cdot 7$ \\
\hline I 8:0 & $6 \cdot 3 \pm 0.41$ & 5.0 & $4.7 \pm 0.37$ & $3 \cdot 8$ \\
\hline $\mathrm{r} 8: \mathrm{x}$ & $6 r \cdot 6 \pm x \cdot 69$ & $50 \cdot 6$ & $55.4 \pm 0.44$ & $45 \cdot 8$ \\
\hline $18: 2$ & $5 \cdot 8 \pm 0.45$ & I $6 \cdot I$ & II $8 \pm 0.41$ & 20.0 \\
\hline $20: 4$ & $0.9 \pm 0.26$ & 0.9 & $1.0 \pm 0.15$ & 0.9 \\
\hline
\end{tabular}

Table 3. Fatty-acid compositions* of the triglycerides isolated from the aortic lesions $\uparrow$ and plasma of rabbits given different atherogenic diets

\begin{tabular}{|c|c|c|c|c|}
\hline \multirow[b]{2}{*}{$\begin{array}{c}\text { Fatty } \\
\text { acid }\end{array}$} & \multicolumn{2}{|c|}{ Butterfat diet } & \multicolumn{2}{|c|}{ Starch diet } \\
\hline & $\begin{array}{l}\text { Aortic } \\
\text { lesions }\end{array}$ & Plasma & $\begin{array}{l}\text { Aortic } \\
\text { lesions }\end{array}$ & Plasma \\
\hline $14: 0$ & $6 \cdot 5 \pm 0 \cdot 56$ & $6 \cdot 5$ & $2.7 \pm 0.22$ & 2.7 \\
\hline I6:0 & $31 \cdot 0 \pm 0.57$ & $3 I \cdot 9$ & $38 \cdot 2 \pm r \cdot 27$ & $35 \cdot 6$ \\
\hline $16: 1$ & $2.8 \pm 0.33$ & $2 \cdot 9$ & $5.7 \pm 0.68$ & 6.0 \\
\hline $18: 0$ & $9.7 \pm 0.94$ & $7 \cdot 8$ & $8.3 \pm 0.47$ & $6 \cdot 3$ \\
\hline I 8: I & $31 \cdot 3 \pm 0.41$ & $28 \cdot 6$ & $33 \cdot 2 \pm 0.90$ & $33 \cdot 6$ \\
\hline I $8: 2$ & $12.5 \pm 0.75$ & 14.4 & $8.4 \pm 0.28$ & $9 \cdot 9$ \\
\hline $20: 4$ & $0.5 \pm 0.14$ & I.O & $0.3 \pm 0.11$ & 0.4 \\
\hline
\end{tabular}

The fatty-acid compositions of the triglycerides isolated from the aortic lesions and from the plasma of rabbits given the different atherogenic diets are shown in Table 3 . There was an overall similarity in the fatty-acid compositions of the lesion and plasma triglycerides but, in the rabbits given either the high-butterfat diet or the high-starch diet, there was a suggestion that the lesion triglycerides contained slightly higher concentrations of stearic and slightly lower concentrations of linoleic acid than did the plasma triglycerides. There was also an overall similarity in the compositions of the unesterified fatty acids present in the aortic lesions and plasma of the rabbits on either dietary treatment, but the unesterified fatty acids in the aortic lesions appeared to 
contain somewhat lower concentrations of palmitic acid and somewhat higher concentrations of oleic acid (Table 4 ).

The fatty-acid compositions of the total phospholipids present in the aortic lesions and plasma of rabbits given the high-butterfat diet or the high-starch diet are presented in Table 5 . In the rabbits on either dietary treatment, saturated fatty acids accounted for over $60 \%$ of the total fatty acids present in the lesion phospholipids but for only about $44 \%$ of the total fatty acids present in the plasma phospholipids. In the lesion phospholipids there were higher concentrations of palmitic, palmitoleic,

Table 4. Compositions* of the unesterified fatty acids present in the aortic lesions $\dagger$ and plasma of rabbits given different atherogenic diets

\begin{tabular}{|c|c|c|c|c|}
\hline \multirow[b]{2}{*}{$\begin{array}{l}\text { Fatty } \\
\text { acid }\end{array}$} & \multicolumn{2}{|c|}{ Butterfat diet } & \multicolumn{2}{|c|}{ Starch diet } \\
\hline & $\begin{array}{l}\text { Aortic } \\
\text { lesions }\end{array}$ & Plasma & $\begin{array}{l}\text { Aortic } \\
\text { lesions }\end{array}$ & Plasma \\
\hline $14: 0$ & $5 \cdot 8 \pm 0.73$ & 5.0 & $4.2 \pm 0.21$ & $3 \cdot 6$ \\
\hline $16: 0$ & $28 \cdot 1 \pm 0.98$ & $34 \cdot 2$ & $30.0 \pm 0.6 \mathrm{I}$ & $35 \cdot 8$ \\
\hline $16: 1$ & $2 \cdot 9 \pm 0.43$ & $2 \cdot 7$ & $5.7 \pm 0.49$ & $5 \cdot 3$ \\
\hline $18: 0$ & $14.9 \pm 0.40$ & I 4.9 & I $3.1 \pm 0.8 \mathrm{I}$ & $\mathrm{II} \cdot 7$ \\
\hline $18: 1$ & $35 \cdot 1 \pm I \cdot 23$ & $29 \cdot 1$ & $33.3 \pm 0.47$ & $29 \cdot 7$ \\
\hline $18: 2$ & $7.6 \pm 0.46$ & 8.5 & $8.1 \pm 0.35$ & $8 \cdot 0$ \\
\hline $20: 4$ & $0.3 \pm 0.04$ & 0.2 & $0.5 \pm 0.06$ & 0.7 \\
\hline
\end{tabular}

Table 5. Fatty-acid compositions* of the total phospholipids isolated from the aortic lesions $\dagger$ and plasma of rabbits given different atherogenic diets

\begin{tabular}{|c|c|c|c|c|}
\hline \multirow[b]{2}{*}{$\begin{array}{l}\text { Fatty } \\
\text { acid }\end{array}$} & \multicolumn{2}{|c|}{ Butterfat diet } & \multicolumn{2}{|c|}{ Starch diet } \\
\hline & $\begin{array}{l}\text { Aortic } \\
\text { lesions }\end{array}$ & Plasma & $\begin{array}{l}\text { Aortic } \\
\text { lesions }\end{array}$ & Plasma \\
\hline $16: 0$ & $39^{\prime 2} \pm 2 \cdot 30$ & $25 \cdot 8$ & $36 \cdot 2 \pm I \cdot 86$ & $26 \cdot 7$ \\
\hline I6:I & $2.6 \pm 0.27$ & 0.8 & $3.4 \pm 0.24$ & $I \cdot 5$ \\
\hline 18:0 & $24 \cdot 3 \pm I \cdot 88$ & $18 \cdot 3$ & $25 \cdot 4 \pm 1 \cdot 97$ & $17 \cdot 2$ \\
\hline 18: I & $18 \cdot 2 \pm 1.05$ & $25 \cdot 9$ & $18 \cdot 9 \pm I \cdot 24$ & $23 \cdot 9$ \\
\hline $18: 2$ & $9 \cdot 6 \pm 1.02$ & $22 \cdot 2$ & $9.5 \pm 0.96$ & $21 \cdot 5$ \\
\hline $20: 4$ & $2 \cdot 0 \pm 0.16$ & $3 \cdot 3$ & $2 \cdot 1 \pm 0.3 I$ & $3 \cdot 5$ \\
\hline
\end{tabular}

Table 6. Compositions* of the phospholipids present in the aortic lesions and plasma of rabbits given different atherogenic diets

\begin{tabular}{lcccc} 
& \multicolumn{2}{c}{ Stasma } & $\overbrace{\text { Aortic lesions }}^{\text {Sutterfat diet }}$ & Plasma \\
Phospholipid & Aortic lesions & $9 \cdot 7$ & $16 \cdot 6$ & $7 \cdot I$ \\
Cephalin & $21 \cdot 2$ & $68 \cdot 8$ & $29 \cdot 7$ & $65 \cdot 1$ \\
Lecithin & $33 \cdot 1$ & $12 \cdot 9$ & $43 \cdot 3$ & $16 \cdot 0$ \\
Sphingomyelin & $36 \cdot 4$ & $8 \cdot 6$ & $10 \cdot 3$ & I I. \\
Lysolecithin & $9 \cdot 3$ & $*$ Expressed as percentages of the total phospholipids.
\end{tabular}


stearic and oleic acids and lower concentrations of linoleic and arachidonic acids than in the plasma phospholipids.

Since the values for the individual phospholipids present in the aortic lesions and plasma were, in each instance, obtained only from a single pooled sample of lesion lipid, the results given in Table 6 must be interpreted with some caution. Nevertheless, the results were reasonably consistent and it would appear that the lesion phospholipids contained markedly higher proportions of cephalin and sphingomyelin and lower proportions of lecithin than did the plasma phospholipids.

\section{DISCUSSION}

The fact that the lipids extracted from the aortic lesions of the rabbits given the high-starch diet contained a higher proportion of triglycerides and lower proportions of cholesterol and cholesterol esters than did the lipids extracted from the aortic lesions of the rabbits given the high-butterfat diet (Table I) is consistent with the earlier observations (Moore, unpublished) on the differences in the amounts of birefringent material in the histological sections of the aortic lesions in rabbits given either of these two atherogenic diets. The results for the lipid composition of the aortic lesions of the rabbits given the high-butterfat diet (Table $\mathrm{x}$ ) were closely similar to those obtained by Böttcher, Woodford, Boelsma-van Houte \& van Gent (I959) and Böttcher, Boelsma-van Houte, ter Haar Romeny-Wachter, Woodford \& van Gent (I960) for the lipids extracted from human atheromatous aortas. Böttcher, Boelsma-van Houte et al. (1960) also showed that, in man, the proportion of triglycerides in the lipids of atheromatous coronary arteries was considerably greater than that in the lipids of atheromatous aortas. It is of interest to note that the lipid composition of the aortic lesions of the rabbits given the high-starch diet was almost identical to that reported by Böttcher, Boelsma-van Houte et al. (I960) for atheromatous coronary arteries in man. The results for the plasma and lesion lipids of rabbits (Table I) are also in agreement with the results of Buck \& Rossiter (I95I) who showed that the ratio of free cholesterol to esterified cholesterol in the atheromatous lesions of human aortas was markedly higher than in the corresponding ratio in human plasma. In rabbits given a commercial diet supplemented with cholesterol and maize oil or with cholesterol and olive oil, Swell, Law \& Treadwell (1962) found that the ratios of free cholesterol to esterified cholesterol in the lipids of the aortas were higher than the corresponding ratios in the serum lipids.

The results in Table 2 are in agreement with those of Zilversmit, Sweeley $\&$ Newman (I96I) and Evrard, van den Bosch, de Somer \& Joosens (I962) who found that the plasma cholesterol esters of rabbits given a diet supplemented with cholesterol contained higher concentrations of linoleic acid and lower concentrations of oleic acid than did the cholesterol esters of the aortas. Somewhat different results were reported by Swell, Law, Schools \& Treadwell (1961) and Swell et al. (I962). Although these investigators found similar concentrations of oleic acid in the cholesterol esters of the serum and aortas of rabbits given diets supplemented with cholesterol, they noted that the serum cholesterol esters contained higher concentrations of linoleic acid and lower concentrations of palmitic acid than did the aortic cholesterol esters. The 
differences in fatty-acid composition of the cholesterol esters in the plasma and aortic lesions of the rabbit (Table 2) are similar to the differences that have been reported by certain authorities to occur between the composition of the cholesterol esters in the serum or plasma and atheromatous lesions in man. For instance, Swell, Field, Schools $\&$ Treadwell $(\mathrm{r} 960 a, b)$ compared the fatty-acid compositions of the cholesterol esters obtained from the serum and from advanced lesions of the abdominal aortas of elderly male subjects with atherosclerosis and found that the lesion cholesterol esters contained higher concentrations of oleic acid and lower concentrations of linoleic acid than did the serum cholesterol esters. These findings of Swell et al. $(1960 a, b)$ are consistent with the earlier observations of Luddy, Barford, Riemenschneider \& Evans (I958), Tuna, Reckers \& Frantz (I958) and Lewis (I958). On the other hand, Wright, Pitt \& Morton (1959) could find no differences in the concentrations of oleic acid in the cholesterol esters present in the plasma and aortic lesions of man. Nevertheless, Wright et al. (I959) did report that the plasma cholesterol esters contained higher concentrations of linoleic acid and lower concentrations of saturated fatty acids than did the lesion cholesterol esters. According to Lawrie ( $196_{3}$ ), there were no differences in the fatty-acid compositions of the cholesterol esters isolated from atherosclerotic plaques and from three different serum lipoprotein fractions in man. However, the plaque lipids analysed by Lawrie (1963) were obtained from fairly advanced lesions and Böttcher, Woodford, ter Haar Romeny-Wachter, Boelsma-van Houte \& van Gent (1960) have shown that the concentration of linoleic acid in the aortic cholesterol esters of man increases with the degree of atherosclerotic involvement. It should be noted that there was no accumulation of trienoic acids in the cholesterol esters obtained from the aortic lesions of the rabbits on either dietary treatment (Table 2). Smith (1962) has reported an increased trienoic: tetraenoic acid ratio in the cholesterol esters of early atheromatous lesions in man. Although this observation suggests that there might have been a localized deficiency of essential fatty acids in the degenerating tissues, the work of Geer \& Malcom (1965) has shown that the trienoic acid that occurs in the cholesterol esters of atheromatous lesions in the human thoracic aorta is $\triangle^{8,11,14}$-eicosatrienoic acid and not $\triangle^{5,8,11}$-eicosatrienoic acid (the fatty acid that accumulates in tissues deficient in essential fatty acids). Since $\Delta^{8,11,14}$-eicosatrienoic acid is an intermediate in the synthesis of arachidonic acid from linoleic acid, it is not surprising that this trienoic acid did not accumulate in the lesion cholesterol esters of the rabbit. The enzyme system that synthesizes arachidonic acid from linoleic acid does not appear to be particularly active in rabbit tissues (Moore $\&$ Williams, $1964 c, d, 1965$ ).

The results for the plasma and lesion trigylcerides of the experimental rabbits (Table 3 ) are consistent with the results reported by other investigators. In experiments with groups of rabbits given various diets supplemented with cholesterol Swell et al. (1961) and Swell et al. (1962) found that, for the animals on each dietary treatment, the fatty-acid composition of the serum triglycerides was almost identical to that of the triglycerides obtained from the atheromatous aortas. Böttcher, Woodford et al. (1960) compared their results for the triglycerides isolated from human atheromatous aortas with those obtained by Schrade, Böhle \& Biegler (I959) for the plasma triglycerides of patients with atherosclerosis and noted a close similarity in the fatty- 
acid compositions of the plasma and aortic triglycerides. In agreement with these findings, Lawrie (1963) reported that the fatty-acid composition of the triglycerides obtained from the atherosclerotic plaques of human aortas was very similar to the fatty-acid composition of the triglycerides obtained from the various lipoprotein fractions in human serum.

In agreement with the results given in Table 5, Swell et al. (1961) have shown that, in rabbits given diets supplemented with cholesterol, the phospholipids of the aortic lesions contained higher concentrations of saturated fatty acids and lower concentrations of linoleic acid than did the serum phospholipids. These observations may be partly explained by the fact that the proportion of sphingomyelin in the lesion lipids was higher than that in the plasma lipids (Table 6). High concentrations of sphingomyelin have been reported to occur in the phospholipids of aortic lesions in the rabbit (Zilversmit et al. 1961) and in man (Weinhouse \& Hirsch, 1940; Buck \& Rossiter, I95 I; Smith, I959; Böttcher \& van Gent, I96r). Zilversmit et al. (1961) have reported that the sphingomyelin isolated from the intimal lesions of rabbits given diets supplemented with cholesterol contains particularly high concentrations of palmitic acid and low concentrations of linoleic acid. Furthermore, the work of Zilversmit $e t$ al. (1961) has shown that the lecithin of the intimal lesions of rabbit aortas contained higher concentrations of saturated fatty acids and lower concentrations of linoleic acid than did the plasma lecithin.

Although there is considerable evidence from experiments with rabbits that the major proportion of the cholesterol present in atheromatous plaques is derived from the plasma rather than from synthesis in the tissues of the aorta (Biggs \& Kritchevsky, 195I; Drury \& Swell, 1960; Schwenk \& Stevens, 1960), it is clear that a simple infiltration of blood lipids into the aortic intima cannot account for the results presented in Tables I and 2. However, the differences in the ratios of free cholesterol to esterified cholesterol in the plasma and lesions are in line with the experiments of Newman, McCandless \& Zilversmit (196I) and Newman \& Zilversmit (I962) which indicated that, in the rabbit, the rate of entry of free cholesterol from the plasma into the aortic intima was greater than that of esterified cholesterol. In spite of the similarities in the fatty-acid compositions of the plasma and lesions triglycerides (Table 3 ) and the fact that triglycerides constituted a higher proportion of the total lipid in both the plasma and the aortic lesions of the rabbits given the high-starch diet, the isotope experiments of Newman et al. (196I) would seem to indicate that the triglycerides present in the atheromatous aortas of rabbits given diets supplemented with cholesterol are synthesized in situ and are not derived from the plasma. A higher rate of triglyceride synthesis in the aortic lesions of the rabbits given the high-starch diet would be in accord with the many reports (e.g. Masoro, Chaikoff, Chernick \& Felts, I950) of enhanced fatty-acid synthesis in the tissues of various experimental animals given diets in which a high proportion of the total calories was derived from carbohydrate. Zilversmit, Shore \& Ackerman (1954), Shore, Zilversmit and Ackerman (1955) and Newman et al. (1961) have shown that the phospholipids in the aortic lesions of the cholesterol-fed rabbit were derived mainly from synthesis in the aortic intima; only a small proportion of the lesion phospholipids was derived from the plasma. The 
marked differences in the fatty-acid compositions of the total phospholipids (Table 5) and in the proportions of the individual phospholipids (Table 6) in the plasma and lesions of the experimental rabbits would thus appear to be a result of the differences in the metabolic origins of the plasma and lesion phospholipids.

The author gratefully acknowledges the encouragement given by Professor S. K. Kon and thanks Miss J. Carrinci, Mr E. V. Ruby and Mr G. Quelch for skilled technical assistance. This study was supported by a grant from the Butter Information Council.

\section{REFERENCES}

Biggs, M. W. \& Kritchevsky, D. (1951). Circulation 4, 34.

Böttcher, C. J. F., Boelsma-van Houte, E., ter Haar Romeny-Wachter, C. Ch., Woodford, F. P. \& van Gent, C. M. (I960). Lancet ii, I I62.

Böttcher, C. J. F. \& van Gent, C. M. (1961). F. Atheroscler. Res. r, 36 .

Böttcher, C. F. J., Woodford, F. P., Boelsma-van Houte, E. \& van Gent, C. M. (1959). Rec. Trav. chim. Pays-Bas Belg. 78, 794 .

Böttcher, C. J. F. ,Woodford, F. P., ter Haar Romeny-Wachter, C. Ch., Boelsma-van Houte, E. \& van Gent, C. M. (1960). Lancet ii, I378.

Buck, R. C. \& Rossiter, R. J. (1951). Archs Path. 5r, 224.

Constantinides, P., Booth, J. \& Carlson, E. (1960). Archs Path. 7o, 712.

Drury, A. \& Swell, L. (1960). Am. F. Physiol. 198, 363.

Evrard, E., van den Bosch, J., de Somer, P. \& Joosens, J. V. (1962). Y. Nutr. 76, 219.

Farquhar, J. W., Insull, W. Jr, Rosen, P., Stoffel, W. \& Ahrens, E. H. Jr (I 959). Nutr. Rev. 17, Suppl.

Folch, J., Lees, M. \& Stanley, G. H. S. (1957). F. biol. Chem. 226, 497.

Geer, J. C. \& Malcom, G. T. (1965). Exp. molec. Path. 4, 500.

Lawrie, T. D. V. (1963). Biochem. Soc. Symp. no. 24, p. Iог.

Lewis, B. (1958). Lancet ii, 7 I.

Luddy, F. E., Barford, R. A., Riemenschneider, R. W. \& Evans, J. D. (1958). F. biol. Chem. 232, 843. Masoro, E. J., Chaikoff, I. L., Chernick, S. S. \& Felts, J. M. (1950). F. biol. Chem. 185, 845.

Moore, J. H. (1962). F. Dairy Res. 29, I4I.

Moore, J. H. \& Doran, B. M. (1962). Biochem. F. 84, 506.

Moore, J. H. \& Kon, S. K. (1963). Chemy Ind. p. 165.

Moore, J. H. \& Williams, D. L. (1963). Can. F. Biochem. Physiol. 41, I82 r.

Moore, J. H. \& Williams, D. L. (1964a). Biochim. biophys. Acta 84, $4 \mathrm{I}$.

Moore, J. H. \& Williams. D. L. (1964b). Br. F. Nutr, 18, 253.

Moore, J. H. \& Williams, D. L. (1964c). Br. F. Nutr. r8, 43 I.

Moore, J. H. \& Williams, D. L. (1964d). Br. F. Nutr. 18, 603.

Moore, J. H. \& Williams, D. L. (1965). Br. $\mathscr{~}$. Nutr. 19, 407.

Moore, J. H. \& Williams, D. L. (1966a). Br. F. Nutr. 20, 79.

Moore, J. H. \& Williams, D. L. (1966b). Br. F. Nutr. 20, 57 I.

Newman, H. A. I., McCandless, E. L. \& Zilversmit, D. B. (196r). F. biol Chem. 236, r264.

Newman, H. A. I. \& Zilversmit, D. B. (1962). F. biol. Chem. 237, 2078.

Noble, R. C. \& Moore, J. H. (1965). Can. F. Biochem. 43, I677.

Schrade, W., Böhle, E. \& Biegler, R. (1959). Klin. Wschr. 37, I Ior.

Schwenk, E. \& Stevens, D. F. (r960). Proc. Soc. exp. Biol. Med. ro3, 6 r 4.

Shore, M. L., Zilversmit, D. B. \& Ackerman, R. F. (1955). Am. $\mathscr{F}$. Physiol. r8r, 527.

Smith, E. B. (1959). Biochem. F. 73, 34 P.

Smith, E. B. (1962). Biochem. F. 84, 49 P.

Swell, L., Field, H. Jr, Schools, P. E. Jr \& Treadwell, C. R. (I960a). Proc. Soc. exp. Biol. Med. ro3, 65I.

Swell, L. Field, H. Jr, Schools, P. E. Jr \& Treadwell, C. R. (1960b). Proc. Soc. exp. Biol. Med. 105, 662.

Swell, L., Law, M. D., Schools, P. E. Jr \& Treadwell, C. R. (196r). F. Nutr. 75, i8ı.

Swell, L., Law, M. D. \& Treadwell, C. R. (1962). F. Nutr. 76, 429.

Tuna, N., Reckers, L. \& Frantz, I. D. Jr (1958). F. ciin. Invest. 37, I 53.

Weinhouse, S. \& Hirsch, E. F. (1940). Archs Path. 29, 3 I.

Wright, A. S., Pitt, G. A. J. \& Morton, R. A. (r959). Lancet ii, 594.

Zilversmit, D. B., Shore, M. L. \& Ackerman, R. F. (1954). Circulation 9, $58 \mathrm{I}$.

Zilversmit, D. B., Sweeley, C. C. \& Newman, H. A. I. (r96r). Circulation Res. 9, 235. 